\title{
Retraction Note to: Identification of profilin 1 as the primary target for the anti-canceractivities of Furowanin A in colorectal cancer
}

\author{
Editorial Office of Pharmacological Reports ${ }^{1}$
}

Published online: 19 November 2020

(c) Maj Institute of Pharmacology Polish Academy of Sciences 2020

\section{Retraction Note to: \\ Pharmacological Reports 71 (2019) 940-949 \\ https://doi.org/10.1016/j.pharep.2019.05.007}

The Editor in Chief retracted this article [1] because of significant concerns regarding Figure 3 presented in this work. After publication, overlap was detected with figures in articles submitted and published within a close time frame, namely Figure 4C in ([2], retracted) and Figure 6C in ([3], retracted). The authors were unable to provide raw data and stated that the figures were obtained through a commercial lab hired to perform some of the experiments for this study. The Editor-in-Chief therefore no longer has confidence in the integrity of the data in this article.

Author Jing LV agreed to retraction but has not stated if they agree to this retraction notice. The remaining authors could not be contacted by the journal.

\section{References}

1. Zhao J, Xu J, Lv J. Identification of profilin 1 as the primary target for the anti-cancer activities of Furowanin A in colorectal cancer. Pharmacol Rep. 2019;71:940-9. https://doi.org/10.1016/j.phare p.2019.05.007.

2. Retracted: Pan X, Wang X, Zhang T. Physcion synergistically enhances the cytotoxicity of sorafenib in hepatocellular carcinoma. Anat Rec. 2019;V302(12):2171-7. https://doi.org/10.1002/ ar.24179.

3. Retracted: Li W, Du H, Zhou G, Song D. Euxanthone represses the proliferation, migration, and invasion of glioblastoma cells by modulating STAT3/SHP-1 signaling. Anat Rec. 2020. https://doi. org/10.1002/ar.24363.

Publisher's Note Springer Nature remains neutral with regard to jurisdictional claims in published maps and institutional affiliations.

The original article can be found online at https://doi. org/10.1016/j.pharep.2019.05.007.

\section{Editorial Office of Pharmacological Reports}

https://www.springer.com/journal/43440 